Klinik Araştırma/Clinical Research

\title{
Ondokuz Mayıs Üniversitesi Tıp Fakültesi cerrahi yoğun bakım ünitesinde yatan 967 hastanın retrospektif analizi
}

\author{
A retrospective analysis of the 967 patients who admitted to the Ondokuz Mayıs University Faculty of Medicine surgical \\ intensive care unit
}

Fatih Özkan* $a$, A. Haydar Şahinoğlu $b$,

${ }^{a}$ Gaziosmanpaşa Üniversitesi Tip Fakültesi Anesteziyoloji ve Reanimasyon AD, Tokat

${ }^{b}$ Ondokuz Mayıs Üniversitesi Tip Fakültesi Anesteziyoloji ve Reanimasyon AD, Samsun

\begin{tabular}{|c|c|}
\hline MAKALE BİLGÍLERİ & ÖZET \\
\hline Makale Geçmişi: & \multirow{10}{*}{$\begin{array}{l}\text { Bu retrospektif çalışma Ondokuz Mayıs Üniversitesi Yoğun Bakım ünitesinde tedavi gören } \\
967 \text { hastanın sonuçlarını değerlendirmek amacıyla yapıldı. Dokuzyüzaltmışyedi hastanın } \\
\text { dosyalarına Ondokuz Mayıs Üniversitesinin arşivinden ulaşıldı. Yoğun Bakım Ünitesine } \\
\text { kabul edilen hastaların yaş, cinsiyet, bölümleri gibi demografik verileri, tanıları ve üniteye } \\
\text { kabul ediliş endikasyonlarına göre dağılımları incelendi. Aynı zamanda bölümlere ve cins- } \\
\text { lere göre yoğun bakım ünitesinde kalış süreleri değerlendirildi. Ayrıca ilaç kullanım oranla- } \\
\text { rı, komplikasyon sıklığı, Glaskow Koma Skalaları ve mortalite hızları da incelendi. } \\
\text { Bu araştırma ile, Ondokuz Mayıs Üniversitesi Tıp Fakültesi Cerrahi Yoğun Bakım Ünite- } \\
\text { sinde takip ve tedavi edilen } 967 \text { hastanın durumunu inceleyen ve sunan ileride danışılabile- } \\
\text { cek ya da daha kapsamlı araştırmalar yapılabilecek bir kaynak oluşturulmak istendi. Ayrıca } \\
\text { Ondokuz Mayıs Üniversitesi Yoğun Bakım Ünitesinin daha iyi ve daha etkin bir duruma } \\
\text { getirilebilmesi için yol gösterici olabilecek bir veri kaynağının hazırlanması amaçlandı. } \\
\text { J. Exp. Clin. Med., 2009; 26:62-67 }\end{array}$} \\
\hline Geliş $\quad 28 / 10 / 2008$ & \\
\hline $09 / 11 / 2009$ & \\
\hline * Yazışma Adresi: & \\
\hline Fatih Özkan & \\
\hline Gaziosmanpaşa Üniversitesi & \\
\hline Tıp Fakültesi Anesteziyoloji ve & \\
\hline Reanimasyon AD Tokat & \\
\hline E-posta : fozkan@gop.edu.tr & \\
\hline Anahtar Kelimeler: & \\
\hline
\end{tabular}

Yoğun Bakım

Retrospektif

Sonuçlar

Analiz

Mortalite

Komplikasyon

\begin{abstract}
The present retrospective study was designed to review the characteristics of the 967 patients who admitted Ondokuz Mayıs University Surgical, Intensive care unit (SICU). We obtained the folders of 967 patients at the archive of Ondokuz Mayis University. The charecteristics of patients who admitted in the SICU according to gender, sex, clinics and diagnosis and admittance indications were investigated. Similarly the length of stay in ICU was determined according to gender and clinics. On the other hand the rates of drugs, the frequency of complications, nutritional support, Glaskow Coma Scale and mortality rates were observed in ICU.

A data source which investigated the situation of 967 patients who were treated in Ondokuz Mayıs Univercity, Medical Faculty ICU was formed to use the results of this study for further investigations as a guide or advisement. In this study, a data source which can be a guide was performed for more effective of Ondokuz Mayıs University Intensive Care Unit.

J. Exp. Clin. Med., 2009; 26:62-67
\end{abstract}

(C) 2009 OMÜ Tüm Hakları Saklıdır.

\section{Giriş}

Yoğun bakım; normal bir hastane servisindeki bakımdan farklı olarak yaşam desteğine gereksinimi olan kritik hastaların sürekli ve spesifik tedavilerinin, bu iş için eğitilmiş personel ve teknolojik cihazlarla donatılmış ünitelerde devam ettirildiği bir süreçtir (Esener, 1997). Hangi büyüklükte olursa olsun her hastane kendi olanaklarına göre vital fonksiyon yetersizliği ile gelen hastaların reani- masyon tedavisini 24 saat garanti altına alacak düzeni kurmalıdır (Fadıllıoğlu ve ark.,1990). Bugünkü uzman doktor, hemşire, teknik personel ve cihazlarla donatılmış, modern tıp eğitimi veren hastanelerin ayrılmaz bir parçası haline gelmiş olan bu özel bakım ve tedavi üniteleri bugünkü düzeylerine yüzyılı aşkın bir zaman içerisinde gelmişlerdir (Şahinoğlu, 1992).

$\mathrm{Bu}$ araştırma; Ondokuz Mayıs Üniversitesi (OMÜ) 
Tıp Fakültesi Cerrahi Yoğun Bakım Ünitesinde (YBÜ) yatan ve tedavi gören hastaları inceleyen ve gelecekte daha kapsamlı araştırmaların planlanmasında danışılabilecek bir kaynak olarak sunuldu.

\section{Araştırma Yöntemi}

YBÜ'nde izlenmiş ve tedavi görmüş 967 hastanın, incelenmeye karar verilen bilgileri YBÜ hasta izlem çizelgelerinden elde edildikten sonra rakamsal olarak kodlanarak istatistiksel bilgisayar programlarından SPSS 10.0'a yüklendi ve tüm verilerin analizinde bu program kullan1larak, dağılım, frekans, ortalama, ortanca, standart sapma, standart hata hesaplarından uygun olanı seçildi. Hasta yaşı ile yoğun bakım ünitelerinde kalış süreleri arasındaki ilişki Non-parametrik Sperman Korelasyon testi ile, yoğun bakımda kalış süreleri ile yıllar arasındaki ilişki MannWhitney U testi ile, hastaların GKS değerleri ile YBÜ'nde kalış süreleri arsındaki ilişki Pearson korelasyon testi ile hastaların yatış, çıkış GKS değerleri ve YBÜ'nden çıkış arasındaki ilişki Student $T$ testi ile değerlendirildi. $p<0,05$ istatistiksel olarak anlamlı kabul edildi.

\section{Sonuçlar}

Retrospektif incelemesi yapilan 967 hastanın \%64,8'i erkek, \%35,2'si kadın hastaydı. Yaşlarına göre hastalar dekatlara ayrilarak incelendi ve en fazla hastanın 3. dekatta olduğu saptandi. Sekizinci dekat ve üzerindeki yaş gruplarında hasta sayısının çok düşük oranlarda kaldığg 1 görüldü $(\% 7,5)$. YBÜ'ne kabul edilen hastaların en büyük bölümünü beyin cerrahisi adına izlenen hastalar oluşturuyordu (\% 39). Bu bölümü kalp-damar cerrahisi $(\% 17,7)$ ve genel cerrahi bölümü $(\% 5,6)$ izledi.

Hastaların 59 farklı klinik tabloyla YBÜ"ne alındı $\breve{g}$, bu klinik tablolar içinde travma kaynaklı olanların \%48 oranında olduğu saptandı. Kafa travmaları tüm travma olgularının \%31,6'sını, tüm hastaların ise \%15,2'sini oluşturuyordu. Hastaların kabul ediliş gerekçesinin en sık postoperatif gözlem $(\% 58,5)$, daha sonra da yakın izlem ve tedavi $(\% 34,6)$ olduğu saptand1. Bu iki endikasyon tüm endikasyonların \%93,1'ini oluşturuyordu (Şekil 1).

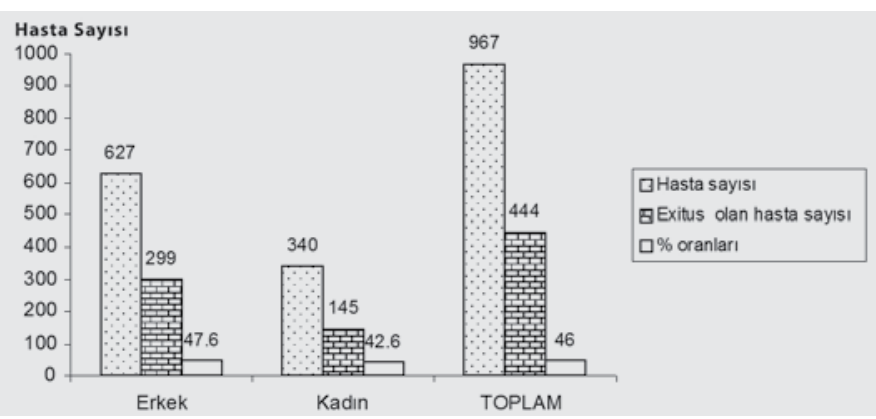

Şekil 1. Mortalite ve \% oranları.

Hastaların YBÜ'nde kalış süresi 1 ile 77 gün arasında değişmekteydi. 967 hastanın kalış süreleri toplamı
7500 gün olarak hesaplandı. Hastaların \%42,4'ü 1- 3 gün arasında, \%14,2'si ise 14 gün veya daha fazla süreyle YBÜ'nde kalmışlardı. Dokuzyüzaltmışyedi hastanın ortanca kalış süreleri 4 gün olarak bulundu. Bölümlere göre kalış süreleri incelendiğinde, İlk ve Acil Yardım bölümü adına yatırılan hastaların 9,5 gün, Beyin Cerrahi bölümü adına yatırılan hastaların ise 7 günlük ortanca kalış süreleri ile ilk sıralarda yer aldıkları saptandı. Hastaların yaşları ile YBÜ'nde kalış süreleri arasında anlamlı bir ilişki bulunamad1. $(\mathrm{p}>0,05)$.

Hastalar yatış durumlarına göre incelendiklerinde, \%42,8'inin entübe şekilde YBÜ'ne yatırıldığ 1 saptand1. Bu hastaların \%40,7'si erkek, \%46,8'i kadındı. Hastalar YBÜ'nden çıkış durumlarına göre de değerlendirildi. Taburcu olarak evlerine $(\% 2,6)$ ya da tedavilerinin sürdürülmesi için kliniklerine $(\% 51,5)$ gönderilen hastaların oranı $\% 54,1$ olarak bulunurken, ölen hastaların oran1 $\% 45,9$ olarak saptandi. (Tablo I).

Tablo I: Yoğun bakım ünitesinden çıkıș durumlarına göre hastaların dağılımı

\begin{tabular}{|l|l|l|l|l|l|l|}
\hline Cinsiyet & Klinik & $\%$ oranlar1 & Taburcu & $\%$ oranları & Exitus & $\%$ oranlar1 \\
\hline Erkek & 313 & 49,9 & 15 & 2,4 & 299 & 47,6 \\
\hline Kadın & 185 & 57,4 & 10 & 2,6 & 145 & 42,6 \\
\hline TOPLAM & 498 & 51,5 & 25 & 2,6 & 444 & 45,9 \\
\hline
\end{tabular}

YBÜ'ndeki ilaç kullanımı incelendiğinde ilk s1rada \%93.1 oranla antibiyotiklerin yer aldığ 1 saptand1. $\mathrm{Bu}$ grubu analjezik ve anestetik ajanlar $(\% 66,4)$ ve steroid ajanlar $(\% 57,9)$ izliyordu. Opioidlerin 967 hastanın 387 sinde $(\% 40,4)$ kullanım oranı ile en çok kullanılan analjezik ve anestetik ilaçlar olduğu saptandı. Diğer ilaçların (antihipertansifler, diüretikler, sempatomimetikler vb.) ise hastaların \%95,4'ünde kullanıldığ1 saptandı.

YBÜ'ne yatırılan hastalarda gelişen ve medikal müdahaleyi gerektiren komplikasyonlar sıklık sırasına göre kardiyak $(\% 63,5)$, solunumsal $(\% 52)$, renal $(\% 23,6)$, septik $(\% 21,8)$ komplikasyonlar olarak saptandı. Bu oranların yıllara dağılımında da bir değiş̧iklik gözlenmedi. Hastaların \%23,8'inde ise herhangi bir komplikasyon görülmedi. Kardiyak ve solunumsal komplikasyonların en sık birlikte görülen komplikasyonlar olduğu belirlendi $(\% 15,7)$. İkiden fazla organ sisteminde yetmezlik veya disfonksiyon gelişmesi olarak tanımlanan multipl organ yetmezliğinin oranı \%38,2 olarak bulundu. Komplikasyonların en az 11- 20 yaş arasında, en fazla 70 yaş ve üzerinde görüldüğü saptand1.

Hastaların \%99,4'üne; parenteral, enteral, ya da her iki yolun birlikte kullanıldığı kombine (enteral+parenteral) yöntemlerden biri beslenme desteği ve tedavi amaciyla uygulanmıştı. Hastalara \%98,8 parenteral, \%33,2 enteral yolla beslenme sağlandığı görüldü. Sadece parenteral yol kullanılan hastaların oranı \%66,2 iken enteral yol kullanılan hastaların oran $1 \% 0,6$ olarak bulundu.

YBÜ'nde prognoz belirleme sistemlerinden Glas- 
kow Koma Skalası (GKS) kullanılıyordu. Hastaların GKS değerleri incelendiğinde 967 hastanın yatıştaki ortalama GKS değeri 7,7 $\pm 0,10$, çıkıştaki ortalama GKS değeri ise $7,1 \pm 0,20$ olarak saptand1. Ayrıca postoperatif takip amaçlı yatırılan hastaların ortalama yatış GKS değerleri $8,1 \pm 0,13$,

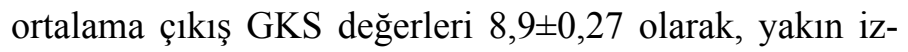
lem amaçlı yatırılan hastaların ortalama yatış GKS değerleri $6,8 \pm 0,10$, ortalama çıkış GKS değerleri 4,08 $\pm 0,30$ olarak bulundu (Tablo II). Hastaların yatıştaki ve çıkıştaki ortalama GKS değerleri karşılaştırıldı ve ayrıca yatıştaki

Tablo II. GKS ile yatış endikasyonları arasındaki ilişki

\begin{tabular}{|l|l|l|l|}
\hline Yatış Endikasyonları & Hasta sayısı & Ortalama Yatış GKS & Ortalama Çıkış GKS \\
\hline Postop takip & 566 & $8,1 \pm 0,13$ & $8,9 \pm 0,27$ \\
\hline Yakın takip ve tedavi & 335 & $6,8 \pm 0,1$ & $4,08 \pm 0,3$ \\
\hline Solunum desteği & 51 & $8,1 \pm 0,4$ & $6,5 \pm 0,9$ \\
\hline TOPLAM & 967 & $7,7 \pm 0,1$ & $7,1 \pm 0,2$ \\
\hline
\end{tabular}

ortalama GKS değeri ile hastaların YBÜ’nde kalış süreleri karşılaştırıldı. Her iki karşılaştırma da istatistiksel olarak anlamlı bulundu $(\mathrm{p}<0,01)$. Bu sonuca göre hastaların yatıştaki ortalama GKS değerleri yükseldikçe, çıkıştaki ortalama GKS değerlerinin de yükseldiği ve YBÜ'nde kalış sürelerinin kısaldığı saptandı. YBÜ'nden taburcu edilen veya kliniklerine gönderilen hastaların yatıştaki ortalama GKS değerleri 9,7 $\pm 0,10$, ölen hastaların yatıştaki ortalama GKS değerleri 5,3 $\pm 0,10$ olarak bulundu. Hastaların yatıştaki GKS değerleri ile YBÜ'nden çıkış durumları arasında istatistiksel bir ilişki olup olmadığ 1 araştırıldığında; YBÜ'ne yatıştaki GKS değeri yükseldikçe, YBÜ'nden taburcu edilme veya kliniklerine gönderilme olasıllı̆ıının $\operatorname{arttığ1~saptandı~}(\mathrm{p}<0,001)$. Ayrıca yatıştaki GKS değeri azaldıkça hastaların ölüm olasılığının arttığı saptandı $(\mathrm{p}<0,001)$.

YBÜ'nin mortalite oranı; cinse,yaşa ve bölümlere göre incelendi. 967 hastanın 444'ü (\% 45,9) ölmüştü. Ölen hastaların \%47,6'sı erkek, \%42,6'sı kadın hastaydı (Şekil 2). Yaş ile mortalite artışının doğru orantılı olduğu görüldü; 0 - 20 yaş arasında $\% 40,5$ iken, 60 yaş ve üzerinde $\% 50$ idi. En fazla hastaya sahip olan beyin cerrahi bölümü hastalarının, mortalite oranının diğer bölümlerden fazla olduğu saptand1 (\%66,2). Bu bölümü genel cerrahi $(\% 55)$ ve kadın hastalıkları ve doğum bölümü $(\% 40,4)$ izlemekteydi.

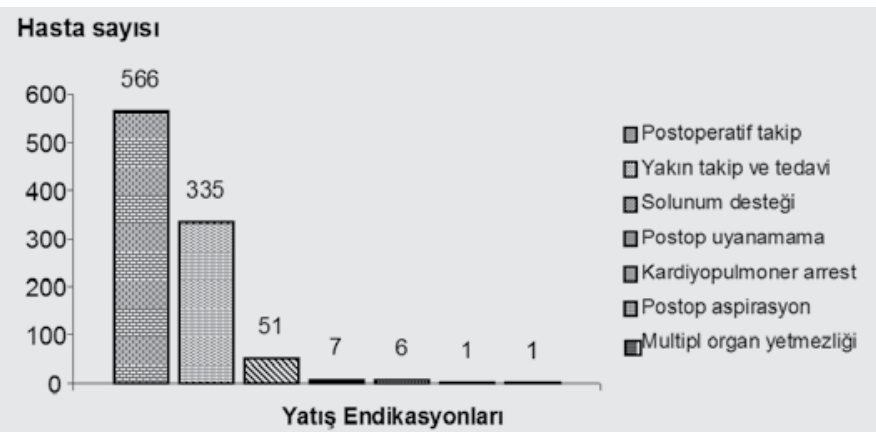

Şekil 2. Hastaların yatış endikasyonlarına göre dağılımı

\section{Tartışma}

$\mathrm{Bu}$ çalışmada cerrahi YBÜ'ne ait (demografik bilgiler, mortalite, komplikasyonlar, kalış süresi, glasgow koma skalası, ilaçlar, beslenme, yatış nedeni, yatış-çıkış şekli) bilgiler temel hatları ile incelendi

Hastanelerde hizmet vermekte olan farklı büyüklüklerdeki yoğun bakım üniteleri incelendiğinde temelde sorunlarının aynı olduğu saptanmıştı (Champion ve ark., 1981; Grenrot ve ark., 1986; Dewar ve ark., 1999). Kullanılan araç ve gereçlerin ileri teknoloji ürünü olması tedavi giderlerinin diğer bölümlere göre oldukça yüksek olması, k1sa periyotlarla tekrarlanan tetkikler gibi nedenlerle özellikle finansmanları kısıtlı hastanelerde yoğun bakım üniteleri zor şartlar altında çalışmak durumundadırlar. Bunun yanı sıra sonuçları olumsuz etkileyen belki de en önemli faktör, tüm yoğun bakım ünitelerinin yaygın bir sorunu ve halen tartışmalı olan YBÜ hasta kabul kriterlerindeki belirsizliktir.

YBÜ'ne kabul edilerek tedavi görmüş ve dosyas1na ulaşabildiğimiz toplam 967 hastanın 627'sini (\%64,8) erkek, 340'ını $(\% 35,3)$ kadın hastalar oluşturuyordu. Çalışmamızdaki bulgulara benzer olarak pek çok çalışmada erkek hastaların yoğun bakım ünitelerine kadın hastalardan daha yüksek oranlarda alındığı saptandı (Rutledge ve ark., 1991; Wichmann ve ark., 2000; Findlay ve ark., 2000; Bari ve ark., 2000).

En fazla hasta beyin cerrahisi bölümü adına yatırılmıştır (\%39). Uludağ Üniversitesinde yapılan bir çalışmada reanimasyon ünitelerinde tedavi gören 1109 hasta retrospektif olarak araştırılmış ve çalışmamıza benzer olarak en fazla hastanın beyin cerrahisi bölümü adına $(\% 19,7)$ yatırıldığı saptanmıştır (Özyurt ve Şahin, 1989). Bu bölümü kalp damar cerrahisi ve genel cerrahi bölümü izlemiştir. Yine bazı çalışmalarda benzer olarak YBÜ'lerine en fazla hastanın beyin cerrahisi bölümü tarafından özellikle de travma sonrasında yatırıldığı saptanmıştır (Frost ve ark., 1981; Fadıllıŏglu ve ark., 1990).

Hastalar 59 farklı klinik tanı ile YBÜ'ne alınmıştı. Bu 59 farklı klinik tabloda gerçek nedenin, \%48'lik oranla travma kaynaklı olduğu saptandı. Travmaların en büyük kısmını kafa travmaları $(\% 31,6)$ oluşturuyordu. Mpe ve ark., yaptıkları bir çalışmada bir yıllık zaman diliminde nörotravmalı 47 hastayı retrospektif olarak incelemişler travmalı hastaların \%66'sının kafa travması olduğunu ve bu hastaların \%81,25'inin primer beyin hasarı nedeni ile öldüklerini bildirmişlerdir (Mpe ve ark,, 2001). Thal yaptığ bir çalışmasında ABD de 1-35 yaş arasındaki ölümlerin en sık nedeninin travmalar olduğunu saptamıştır (Thall, 1991) Ondokuz Mayıs Üniversitesi YBÜ'ne kliniği ağır olan vakaların kabul edilmesi ve kabul edilenlerin de büyük bir kısmının ciddi travma vakası olması yoğun bakım ünitesinin sonuçlarını olumsuz etkilediği kanısındayız. 
Hastaların YBÜ'ne 7 değişik endikasyon ile kabul edildiği saptandı. YBÜ'ne yatırılan tüm hastaların $\% 58,5$ 'inin postoperatif gözlem, \%34,6'sının yakın takip ve tedavi gerekliliği nedeni ile kabul edildiği görüldü. $\mathrm{Bu}$ iki yatış endikasyonu tüm yatış endikasyonlarının $\% 93,1$ 'ini oluşturmaktaydı. Staudinger ve ark 66 aylık periyotta 414 kanserli yoğun bakım hastasını izlemişler ve en sık yatış endikasyonunun postoperatif gözlem olduğunu saptamışlardır (Staudinger ve ark., 2000). Yapılan çok sayıda çalışmada YBÜ'ne kabul edilen hastaların kalış sürelerinin de incelendiği görüldü. Findlay ve ark., Ocak 1993- Aralık 1994 tarihleri arasında yoğun bakım ünitelerine kabul ettikleri 774 hastayı incelemişlerdir. Hastaların YBÜ'nde kalış sürelerinin 1-68 gün arasında değiştiğini ve YBÜ'nde kalış sürelerinin ortanca değerinin 2 gün olduğunu bulmuşlardır (Findlay ve ark., 2000). Weissman 8 yıllık süreçte YBÜ'nde izledikleri 6571 hastanın toplam yatış sürelerini 26825 gün olarak hesaplamışlardır. Hastaların YBÜ'nde kalış sürelerinin 1-147 gün arasında değiştiğini ve hastaların ortanca kalış sürelerinin 2 gün olduğunu belirlemiştir (Weissman, 2000). Çalışmamızda 967 hastanın toplam kalış süreleri tam olarak 7500 gün olarak bulundu. Hastaların kalış sürelerinin ortanca değeri 4 gün olarak saptandı. Kalış süreleri 1-77 gün arasında değişmekteydi. 967 hastanın \%42,4'ünün kalış süresi 1-3 gün arasında değişmekteydi. 14 gün ve üzerinde YBÜ'nde kalanların oranı ise \%14,2 olarak saptand1. En uzun süre yatan hastaların Acil servisten gelen hastalar olduğu ortanca kalış sürelerinin 9,5 gün olduğu saptandı.

Zaren ve Bergström çalışmalarında YBÜ'ne kabul ettikleri 978 hastanın \%47'sinin mekanik ventilasyona gereksinim duyduklarını saptamışlardır (Zaren ve Bergström, 1988). Yaptıkları diğer bir çalışmada 980 hastayı incelemişler, YBÜ'ne yatışta mekanik ventilasyona gereksinim duyanların, spontan soluyan hastalara göre yaşam şansının daha az olduğunu saptamışlardır (Zaren ve Bergström, 1989). Biz çalışmamızda ayrıca mekanik ventilasyona gereksinim duyan hastaların oranın $1 \% 42,8$, ünitemizin mortalite oranın $1 \% 46$ olarak bulduk. Aralarında istatistiksel bir analiz uygulamamakla birlikte, oranlar arasında rakamsal bir yakınlık görülmektedir.

Çalışmamızda analjezik ve anestetik ajan kullanımını incelendiğinde ilaç kullanımının giderek arttığı ve $\% 50,8$ 'den $\% 76,3$ 'e yükseldiği saptand1. Analizi yapılan süreçte yıldan yıla analjezik ve anestetik ajan kullanımındaki artışın hastaların YBÜ'nde kalış süresinin uzaması, sedasyon, analjezi ve anestezi gereksiniminin artması, kullanılan sedatif, analjezik ve anestetik ajanların çeşit olarak artmas1, kolay bulunabilmeleri, solunumsal ve kardiyak yan etkiler gibi olumsuz etkilerini azaltacak yöntem ve teknik araçların geliştirilmesi ile dozların daha kontrollü verilebilmesi gibi nedenlerden kaynaklanabileceği düşü- nüldü. Antibiyotik kullanımındaki yüksek oran hastalarda enfeksiyon olup olmamasına bakılmaksızın yoğun olarak kullanılmasıyla açıklanabilir.

Çalışmamızda 967 hastada gelişen komplikasyonlar incelendiğinde; YBÜ'ne kabul edilen hastaların $\% 23,8$ 'inde her hangi bir komplikasyon gelişmediği saptanmıştır. Çoğu araştırmacı ise organ yetersizliğini var ya da yok şeklinde düşünür ve şiddetini yetersizliği ve disfonksiyonu olan sistemlerin sayısı ile açıklar (Thal, 1991; Bone ve ark., 1992; Mpe ve ark., 2001). Multipl organ yetersizliği sendromu gelişmesi açısından çalışmamızda ikiden fazla organ sisteminde disfonksiyon gelişen hasta sayısı araştırıldı ve 967 hastanın \%38,2'sinde ikiden fazla komplikasyon geliştiğini saptandı. Komplikasyon sıklığ1nın \%76,2 gibi yüksek bir oranda olması ve multipl organ yetersizliği sendromu gelişmesi açısından incelendiğinde ikiden fazla komplikasyon gelişen hastanın \%38,2 olmas1 yoğun bakım ünitesini olumsuz etkilediği söylenebilir. Multipl organ yetersizliğinde mortalitenin \%60-70'lerin üzerinde olduğu, üçten fazla organ yetersizliğe girdiğinde mortalite oranının \%90'dan fazla olduğu bildirilmiştir (Wenzel ve ark., 1983; Daschner, 1985; Marshall ve ark., 1995).

YBÜ'nde beslenme desteği ve tedavisi; enteral, parenteral veya her iki beslenme yönteminin bir arada kullanılması ile sağlanır. Parenteral nütrisyonun tek endikasyonu gastrointestinal sistemin kullanılamaması ve fonksiyonel olmamasidır. Kontrendikasyonu ise oral yoldan veya enteral tüple besinlerin yeterince alınabilmesi ve emilebilmesidir. Ancak çalışmamızda YBÜ’ndeki enteral beslenmenin beklenen ve istenilenin aksine düşük oranda olduğu saptandi.

GKS (Glasgow Coma Skalasi); 1974 y1lında Teasdele ve Jannett tarafindan kafa travmalarının şiddetini ve derinliğini değerlendirmek için geliştirilmiştir (Teasdele ve Jannett, 1974). Çalışmamızda 967 hastanın GKS değerleri incelendi. Hastaların YBÜ'ne kabullerindeki GKS değerleri ile YBÜ'nden çıkış durumları arasında anlamlı bir ilişki olduğu saptandı. Hastaların YBÜ'ne yatıştaki GKS değerleri yükseldikçe hastaların kliniklerine veya taburcu edilerek evlerine gönderilme olasılığ 1 artıyordu. Hastaların GKS değerleri azaldıkça ölüm olasılığının yükseldiği saptandi. Teoh ve ark., 1994-1998 yılları arasında yoğun bakım ünitelerinde takip ve tedavi gören 1390 hastayı incelemişlerdir. GKS'nın mortalite ile olan ilişkisini araştırmışlar ve aralarında anlamlı bir ilişki bulmuşlardır (Teoh ve ark., 2000). Mpe ve ark. 1999 yılında yaptıkları retrospektif bir çalışmada travmalı hastalarda mortalite oranının yüksek olduğunu, YBÜ'ne yatış sırasında GKS değerleri 4 ve altında olan hastaların prognozunun kötü olduğunu saptamışlardır ve GKS değeri düşük hastaların çok azının tam olarak iyileşebileceğini belirtmişlerdir (Mpe ve ark., 
2001). Çalışmamızda YBÜ'nin mortalitesinin yüksek olması ve sonuçlarının kötü olmasının nedeni olarak GKS değeri 5 'in altındaki hastaların YBÜ'ne yüksek oranda kabul edilmesinden kaynaklandığı saptandı. YBÜ'ne yatıştaki GKS değeri yüksek olan hastaların YBÜ’nde kalış sürelerinin kısa olduğu görüldü. Ayrıca YBÜ'ne yatıştaki GKS değerleri ile çıkıştaki GKS değerleri karşılaştırıldığında; yatıştaki GKS değeri yükseldikçe çıkış GKS değerinin arttı̆̆ı, yatıştaki GKS değeri düştükçe çıkış GKS değerinin azaldığg saptandı.

Çalışmamızda retrospektif yaşam analizi yapıldığında 967 hastadan 444'ünün ölmüş olduğu ve YBÜ'nin mortalitesinin \%46 olduğu saptand. Yaşla birlikte mortalitenin arttığ $10-20$ yaşta \%40'lara, 60 yaş ve üzerinde \%50'lere ulaştığı saptandı. ABD'de yoğun bakım ünitelerinde yapılan bir çalışmada 2693 hasta incelenmiş çalışmamıza benzer olarak yaşla mortalitenin arttığı belirtilmiştir (Champion ve ark., 1981). Grenrot ve ark yaşlı bireylerde retrospektif olarak yaptıkları bir çalışmada hastaların YBÜ'ne kabulünden sonraki bir aylık dönemde mortalite hızının \%44, bir yıllık dönemde ise $\% 53$ olduğunu saptamışlar ve yaşla birlikte mortalitenin arttığını çalışmalarında belirtmişlerdir (Grenrot ve ark., 1986). Benzer olarak pek çok araştırıcı yoğun bakım ünitelerinin mortalitelerini karşılaştırmış, yaşla aralarında anlamlı bir ilişkinin olduğunu ortaya koymuşlardır.

Bölümlere göre mortaliteyi incelendiğinde YBÜ'ndede tüm bölümlere oranla en fazla hastaya sahip olan beyin cerrahisi bölümünün mortalitesinin de en yük- sek (\%66,2) olduğu görüldü. Türkiye'de 1982-1988 yıllar1nı kapsayan bir çalışmada 1109 hasta incelenmiş YBÜ'nin toplam mortalitesi \%32 oranında iken 219 beyin cerrahi hastasında mortalite \%69 olarak saptanmıştır (Özyurt ve Şahin, 1989).

Yoğun bakım ünitelerindeki mortalite oranı başarının değerlendirilmesi için uygun bir ölçüt değildir. Çünkü yoğun bakım ünitelerinde olan ölümlerin hastaların YBÜ'ne yatış tarihinden sonraki iki yılık süreç içinde görülen ölümlerin 1/3'ünden daha azını oluşturduğu belirtilmişti (Daschner, 1985). Le Gall mortalitenin ve yaşam şansının değerlendirilmesi için YBÜ'ne yatıştan sonraki 6 aylık izlem peryodunun uygun olduğunu ileri sürmüştür (Le Gall ve ark., 1981). Çünkü mortalite farklı taburcu etme politikaları, sosyo-ekonomik durum, hastanın transferi ve YBÜ'ne kabulündeki farklı politikalardan etkilenebilmektedir.

\section{Sonuç}

Yoğun bakım ünitelerine alınacak hastaların seçiminde belli kriterler olmalıdır. Hasta kabulündeki sorunların YBÜ'nin sonuçlarını etkileyen, mortaliteyi artıran ve kalış süresini uzatan önemli faktörlerden biri olduğu görülmektedir. Bu araştırma ile, Ondokuz Mayıs Üniversitesi Tıp Fakültesi Cerrahi YBÜ’nde takip ve tedavi edilen 967 hastanın retrospektif analizi sunan ve YBÜ'nin gelecekteki hedefleri ve sonuçları için yol gösterici olabilecek bir kaynak oluşturulmuştur.

\section{KAYNAKLAR}

Bari, M. D., Chiarlone, M., Fumagalli, S., Boncinelli, L., Tarantini, F., Ungar, A, 2000. Cardiopulmonary resuscitation of older, inhospital patients: Immediate efficacy and long-term outcome. Crit. Care Med. 28, 2320-2325.

Bone, R. C., Balk, R., Slotman, G., Maunder, R., Silverman, H., Hyers, T. M., Kerstein, M. D, 1992. Adult respiratory distress syndrome. Sequence and importance of development of multiple organ failure. Chest 101, 320-326.

Champion, E. W., Mulley, A. G., Goldstein, R. L., Barnett, G. O., 1981. Thibault, G. E. Medical intensive care for the elderly. JAMA 246, 2052-2056.

Daschner, F, 1985. Nasocomial infections in intensive care units. Intens. Care Med. 11, 284-287.

Dewar, D. M., Kurek, C. J., Lambrinos, J., Cohen, I. L., Zhong, Y, 1999. Patterns in costs and outcomes for patients with prolonged mechanical ventilation undergoing tracheostomy: An analysis of discharges under diagnosis related group 483 in New York State from 1992 to 1996. Crit. Care Med. 27, 2640-2647.

Esener, Z, 1997. Klinik Anestezi 2. Baskı. Logos Yayıncılık Tic. A.Ş., İstanbul, 696-699.

Fadıllığlu, S., Bayraktarkatal, S., Üye, M., Aşçı, N., 1990. Taksim Hastanesi Reanimasyon Ünitesinde $1985-1990$ yılları arasında tedavi edilen Hastaların Analizi. Taksim Hast. Tıp Bült. 48-51.

Findlay, J. Y., Plenderleith, J. L., Schroeder, D.R, 2000. Influence of social deprivation on intensive care outcome. Intensive Care Med. 26, 929-933.

Frost, E. A., Kim, B., Thragarajah, S, 1981. Anaesthesia and outcome in severe head injury. Br. J. Anaesth. 53, $301-306$.

Grenrot, C., Norberg, K.A., Hakansson, S, 1986. Intensive care of the elderly: a retrospective study. Acta Anaesthesiol. Scand. 30, 703-708.

Le Gall, J., Loirat, P., Alperovitch, A. 1981. A simplified acute physiology score for ICU patients. Crit. Care Med. 9, 591.

Marshall, J. C., Cook, D. J., Christou, N. V, 1995. Multiple organ dysfunction score. A reliable descriptor of a complex clinical outcome. Crit. Care Med. 23, 1638-1652. 
Mpe, M. J., Mathekga, K., Mzileni, M. O, 2001.The outcome of neuro-truma. A 1 year retrospective study in an intensive care unit. Critical Care. 5, 115-119.

Özyurt, G., Şahin, Ş, 1989. Reanimasyon ünitesinde 1982-1988 yılları arasında tedavi edilen hastaların analizi. Türk Anest. ve Rean. Cem. Mec. 17, 161-163.

Rutledge, R., Fakhry, S. M., Rutherdford, E. J., Muakkassa, F., Baker, C. C., Koruda, M., Meyer, A.A, 1991.Acute Physiology and Chronic Health Evaluation (APACHE II) score and outcome in the surgical intensive care unit: An analysis of multiple intervention and outcome variables 1238 patients. Crit. Care Med. 19, 1048-1053.

Staudinger, T., Stoiser, B., Müllner, M., Locker, G. J., Laczika, K, 2000. Outcome and prognostic factors in critically ill cancer patients admiddet to the intensive care unit. Crit. Care Med. 28, 1322-1328.

Şahinoğlu, H, 1992. Yoğun Bakım Sorunları ve Tedavileri 1. Baskı. Türkiye Klinikleri Yayınevi. Ankara. 3-8.

Weissman, C, 2000. Factor influencing changes in surgical intensive care unit utilization. Crit. Care Med. 28, 1766-1771.

Wenzel, R. P., Thompson, R. L., Landry, S. M., Russel, B. S., Miller, P. J, 1983.Hospital acquired infections in intensive care unit patients. An overview with emphasis on epidemics. İnfect. Control. 4, 371-375.

Wichmann, M.W., Inthorn, D., Andress, H.j.,Schildberg, F.W, 2000. Incidence and mortality of severe sepsis in surgical intensive care patients: the influence of patient gender on disease process and outcome. Intensive Care Med. 26, 167-172.

Teasdele, G., Jennett, B, 1974. Assessment of coma and impaired consciousness: a practical scale. Lancet, 81-83. 